\section{Due process protection}

SIR-In an article headed "Investigators investigated" (Nature 346, 9; 1990), Christopher Anderson attributed to one of us, Suzanne Hadley, the assertion that "full due process" [the US term for such rights as appeal, hearing and cross-examination in a legal proceeding] is "inappropriate for OSI" (Office of Scientific Integrity).

We wish to make it clear that due process protection is reflected in all aspects of OSI procedures from start to finish. The due process protection in an investigation differs from that obtaining in a court of law or a hearing before an administrative law judge, but concern for due process is always appropriate for the OSI.

Specifically, the respondent in an OSI investigation receives formal notice of the investigation, together with a clear and complete statement of the issues that are the focus of the investigation. Respondents may be represented by counsel, and may provide any evidence and information they believe is relevant. They are presented with the evidence developed by the OSI and given an opportunity to respond, both in interviews and in written submissions. All interviews are recorded and transcribed, and the person interviewed has an opportunity to review, correct and comment on the transcript.

At the conclusion of an OSI investigation, the respondent (as well as the informant) is given the opportunity to review and rebut or comment on the draft report. Comments are appended directly to the report, which is revised and/or expanded, as appropriate. If misconduct is found, and sanctions proposed, the respondent has a further opportunity to review and comment on them.

Beyond the OSI, a careful process of review provides ample checks and balances on OSI investigations. Findings and recommendations together with the respondent's comments or rebuttal are reviewed by the relevant agency director and by the Office of Scientific Integrity Review. The Assistant Secretary for Health also reviews the findings and recommendations, before making the final decision. If debarment from receiving federal grant and contract funds is recommended, an oportunity for a new hearing is provided.

JULES V. HaLlum (Director)

SUZANNE W. HADLEY (Deputy Director)

Office of Scientific Integrity,

National Institutes of Health,

Building 31, Room B1C39,

Bethesda,

Maryland 20892, USA

\section{Grant-making}

SIR-With reference to your leading article ("Untransparent grants", Nature 346,$684 ; 1990$ ), it is difficult to see how we in the Medical Research Council could be more transparent about our decisionmaking processes without engaging in a public discussion of the merits and demerits of individual research proposals. We do not consider that this would be in the best interests of the research community.

It should not be surprising that there is not total unanimity of view at the various stages of the peer review process referees, visiting subcommittees and research board. Indeed, if there were, the procedure could be greatly simplified. At each stage, a wider scientific perspective is introduced. Research boards have to take account of how the quality of work in one research field compares with that of another. What is excellent in one field may not be so excellent when judged against competing claims from other fields and so the council is necessarily having to decline some applications that receive glowing testimonials from referees. These are the very difficult judgements that the peer review system is constantly having to make. They are judgements that have to be made regardless of wider considerations of scientific strategy, which are themselves made public in our corporate strategy document.

Medical Research Council,

D. A. REES (Secretary)

20 Park Crescent, London W1N 4AL, UK

\section{Tenure in Japan}

SIR-There is a curious omission in Robert J. Geller's otherwise quite sensible argument about the limited tenure positions available to foreign staff members in Japanese universities (Nature 345, $380 ; 1990)$.

Tenured academic appointments in Japanese universities presuppose proficiency in written and spoken Japanese, in which all formal administrative procedures are carried out, including faculty and committee meetings as well as work in labour unions and professional associations. Exemption from these duties for a foreign faculty member because of linguistic limitation will certainly invite complaints from Japanese faculty members, if only because of the unequal amounts of time to be sacrificed to activities other than creative scientific work.

The participation of more non-Japanese faculty staff in the running of Japanese universities would be welcome. But to expect bilingualism in Japanese and English in the administrative process is ludicrously utopian in the current ambience. Can anyone with experience in
Japanese universities suggest a possible way out of this perennial dilemma? Or should we expect there to be a cohort of competent scientists in the world with sufficient proficiency in Japanese to enable them to start with half the burden of administrative work, that, apart from the teaching job, the average Japanese academic must expect to shoulder?

Faculty of Humanities,

Kyoto Seika University,

Iwakura, Sakyo-ku, Kyoto 606, Japan

\section{Clinicians wanted}

SIR-Those responsible for preclinical education generally strive to expose medical students both to the newest developments in science and to the application of established science to the understanding of disease and its treatment. The effective teaching of clinical and applied science depends particularly on members of staff with a medical qualification. In contrast to those teaching much of biophysical, chemical and molecular science, medical graduates are recruited in competition with hospitals and other such institutions, which in turn compete with private clinical organizations. The young medical graduate contemplating a career in medical science usually has to accept a substantial reduction of career income.

John P. Gibson (Nature 346, 213; 1990), who asks what possible purpose can be served by separate salary scales for medical and science graduates, thus answers himself correctly when he observes that the purpose is recruitment. The principles are no different from those he can see in North America. In New Zealand, current university scales have all been negotiated in a common procedure; major considerations have been the problems of recruitment and retention of staff. The irritation produced by the formal distinction of the two different salary scales has to be contrasted with the academic disaster that followed adoption of a single scale some years ago. The alternatives practised elsewhere are not attractive: to maintain secret ways of meeting the market value of particular staff or, less palatable still, overtly or covertly to restrict preclinical teaching posts to medical graduates and thus to restrict the view of medical science to which future doctors are to be exposed.

Your correspondent is wrong in one major conclusion - our difficulty is not to attract first class scientists but to find graduates who can teach medical science from the secure base of personal experience in both preclinical and clinical elements of the curriculum faced by their students.

Department of Physiology,

J. D. SINCLAIR

University of Auckland, New Zealand 